PRINT ISSN 1119-8362

Electronic ISSN 1119-8362
Full-text Available Online at

https://www.ajol.info/index.php/jasem

http://ww.bioline.org.br/ja
J. Appl. Sci. Environ. Manage.

Vol. 25 (7) 1139-1146 July 2021

\title{
Estimating Aboveground Biomass Using Allometric Models And Adaptive Learning Rate Optimization Algorithms
}

\author{
*OKONKWO, SJ; MSHELIA, ZH
}

Department of Environmental Modelling and Biometrics, Forestry Research Institute of Nigeria, Ibadan

*Corresponding Author Email: sj.okonkwo@gmail.com

\begin{abstract}
Forest aboveground biomass (AGB) is imperative in the study of climate change and the carbon cycle in the global terrestrial ecosystem. Developing a credible approach to estimate forest biomass and carbon stocks is essential. Four allometric models were used with two optimization algorithms; Modified Root Mean Square Propagation (Modified RMSProp) and Modified Adaptive Moment Estimation (Modified Adam) were also used to train each model. Convergence was achieved after 1000 iterations of Modified RMSProp and 200 iterations of Modified Adam for all the models. A learning rate of 0.01 and exponential decay rates of 0.9 and 0.999 for the first and second momentum. A loss function of 0.5 Mean Square Error (0.5 MSE) was used and Root Mean Square Error (RMSE) was used to judge the accuracy of the models. The study showed that the optimization algorithms were both able to accurately optimize three of the four allometric models. While Modified Adam was the more efficient optimizer, it had the highest RMSE value 2.3910 and Modified RMSProp had the least RMSE value 0.37381 . However, there was no statistically significant difference between the accuracy of the models optimized by both algorithms.
\end{abstract}

\section{DOI: https://dx.doi.org/10.4314/jasem.v25i7.6}

Copyright: Copyright $(2021$ Okonkwo and Mshelia. This is an open access article distributed under the Creative Commons Attribution License (CCL), which permits unrestricted use, distribution, and reproduction in any medium, provided the original work is properly cited.

Dates: Received: 10 May 2021; Revised: 28 June 2021; Accepted: 01 July 2021

Keywords: Aboveground Biomass, Decay Rate, Modified Adam, Modified RMSProp

Forest is the most important and largest terrestrial ecosystem that plays important role in maintaining and promoting global ecological balance and biological evolution and community succession (Brown, 2002; Houghton, et al., 2009). Forest aboveground biomass (AGB) is an important variable in the study of climate change and the carbon cycle in the global terrestrial ecosystem. Estimating the biomass accurately is key in understanding the carbon cycle of the terrestrial ecosystem in large areas (Lu, et al., 2005; Li, et al., 2015). Therefore, developing a credible approach to estimate forest biomass and carbon stocks is essential. The forest above-ground biomass is mainly estimated using two methods, the traditional field measurements (West, 2016) or remote sensing techniques (Lu, 2006). The two methods are used together to achieve accuracy over a large area. The traditional field measurement gives a more accurate estimate but it is not feasible on a large area as it is labour intensive, too costly and time-consuming. Previous studies have shown that remote sensing can effectively measure AGB at a regional scale, hence both the passive and active sensors have been used to estimate AGB (Deng, 2014; Cao, et al., 2016; Shen, et al., 2016). To be able to accommodate the complex relationship between forest AGB and other predictor variables that cannot be fully captured by conventional statistical regression methods, when creating allometric models, it is important not to assume a linear relationship between the dependent and independent variables of regression models as is the case with most early biomass estimation studies (Le et al., 1992; Dong, et al., 2003). Machine learning methods and optimization algorithms can accommodate complex non-linear relationship between predictor variables and predicted variables, and improve the accuracy of the prediction (Ali, et al., 2015; Baghdadi, et al. 2015). Research questions such as: can RMSProp and Adam be able to optimize allometric models? Which of the optimization algorithms is more efficient at optimizing allometric models? This study seeks to evaluate the adaptive learning rate optimization algorithms on the allometric model and to determine its efficiency in calculating and predicting above-ground biomass with the main purpose of coming up with allometric equations for estimating aboveground biomass in tropical regions.

\section{MATERIALS AND METHODS}

Study Area: The Omo Forest Reserve, which derives its name from River Omo that traverses it, is located between latitudes $6042^{\prime}$ to $7^{\circ} 05^{\prime} \mathrm{N}$ and longitude $4^{\circ}$ $12^{\prime}$ to $4^{\circ} 35^{\prime}$ E (Figure 1) Ogun state South-western Nigeria. Omo covers about 130,500 hectares, which 
includes a 460 ha Strict Nature Reserve (Okali and Ola-Adams, 1987). The climate is tropical and it is characterized by wet and dry seasons. The temperature ranges between 21 and $34^{\circ} \mathrm{C}$ while the annual rainfall ranges between 150 and $3000 \mathrm{~mm}$ (Larinde et al., 2011; Adedeji et al., 2015).

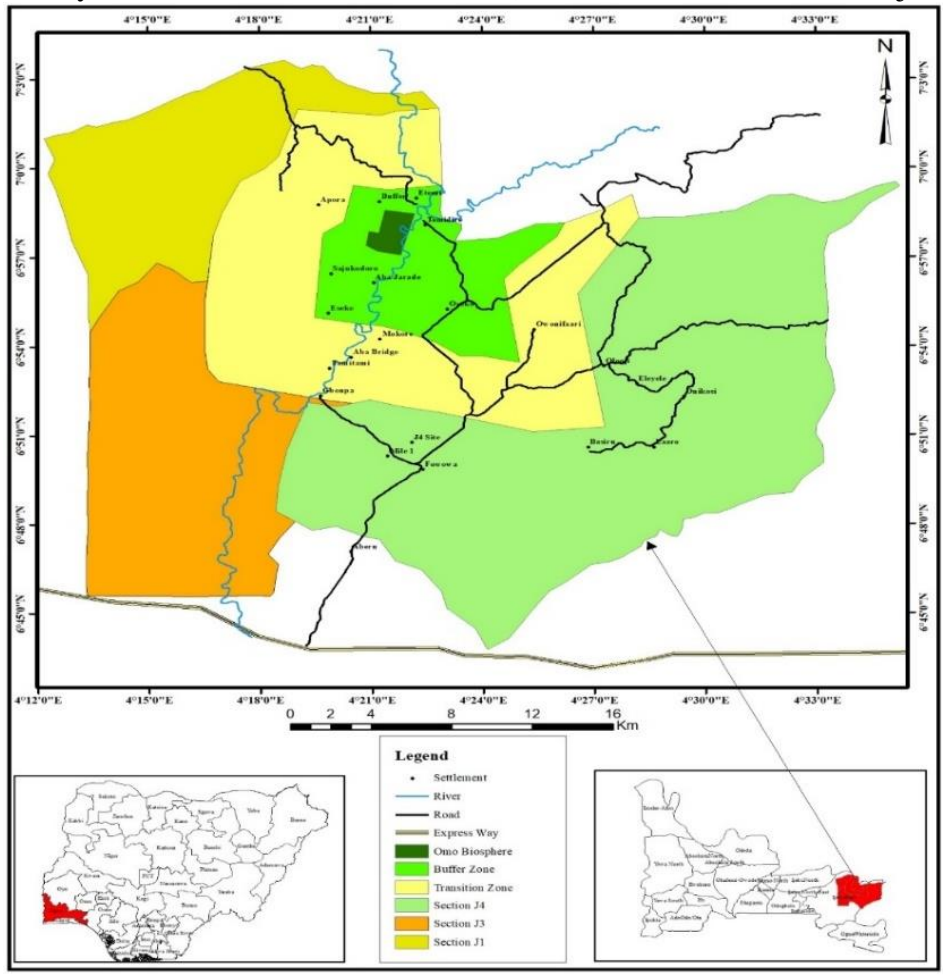

Fig 1: Omo Forest Reserve

Data Collection: A Forest inventory-based approach was adopted to estimate above-ground tree biomass in the study areas. Transects were distributed over the entire forest, using a systematic segmented grid (Buckland et al., 2004) randomly superimposed onto the area. The forest inventory was conducted in 50 plots of $30 \mathrm{~m}$ x $30 \mathrm{~m}$ sample plots randomly laid in the forest reserve. The structural variables such as diameter at breast height $(\mathrm{DBH}) \geq 20 \mathrm{~cm}$, tree height and wood density were recorded in the field. The structural information obtained was used to estimate the AGB, which is the total amount of living organic material of trees. Field measurement of tree variables was carried out using relascope, Haga altimeter, increment borer, scale weight, measuring tape, ranging pole and Global Positioning System (GPS).

\section{Determination of Biomass and Carbon Stock in the} Study Area

Measurement of total height: This is the vertical distance between the ground level and the tip of a tree. It is obtained by taking the reading at the top (RT) and reading at the base (RB) which is usually negative (when on an elevated ground) and positive (when in a depressed ground or valley). It was measured with the aid of Spiegel Relaskop. The formula used to obtain the total height $(\mathrm{H})$ using the metric scale is:

$$
H=R T-R B
$$

Where $H$ is the height, $R T$ is the reading at the top, and $R B$ is the reading at the base.

Measurement of Tree diameter at Breast Height $(D B H)$ : This is the diameter measurement taking for a standing tree at height $1.30 \mathrm{~m}$ above the ground level. This tree parameter was taken for trees within the permanent sample plots. This measurement is generally accepted in forest inventory. It is the easiest measurable parameter in forest inventory with a high degree of accuracy where guiding rules are followed. It was measured with the aid of diameter tape in centimetre $(\mathrm{cm})$.

Diameter at the middle $(\mathrm{Dm})$ and diameter at the top $(D t)$ was also measured at various positions on the standing tree using Spiegel Relaskop. Readings for $D m$ and $D t$ were taken in terms of numbers of bands of the relaskop occupied by the stem of the trees both at the middle and the top. These bands of relaskop are of two types, dark bands which are one unit each and big white bands which are four units each. The readings were taken by standing at a specified distance from the tree whose diameter is to be measured. 
Wood Density: To determine the specific wood density, core samples were collected for each species at breast height. The specific wood density is the arithmetic average value of all samples of a species and was calculated as oven-dry weight divided by the fresh volume of each sample. The inner diameter of the bit of the increment borer device was $0.5 \mathrm{~cm}$ leading to a diameter of the sample of $0.5 \mathrm{~cm}$. The length $\mathrm{L}$ of the sample was measured after its extraction. The oven-dry density $(\rho)$ in terms of dry mass per fresh volume $\left(\mathrm{g} \mathrm{cm}^{-}\right)$of all collected wood samples was estimated using:

$\rho=\frac{4 d M S i}{\pi d^{2} L i}$

Where $d M S i$ is the dry mass of wood sample $i$ obtained by the increment borer, $d$ is the diameter of the bit, and $L i$ is the length of the sample $i$.

\section{Data Processing}

Basal Area Estimation: Tree Basal Area (TBA) is the cross-sectional area (over the bark) at breast height (1.3 metres above the ground) measured in metres squared $\left(\mathrm{m}^{2}\right)$. The TBA can be used to estimate tree volumes and stand competition. The Tree Basal Area was determined by measuring the diameter at breast height in centimetres and the basal area $\left(\mathrm{m}^{2}\right)$ was calculated using an equation based on the formula for the area of a circle (area $=\pi r^{2}$ where $r=$ radius and $\pi=3.142)$ and the formula for radius $(r=$ diameter $/ 2=D B H / 2)$.

$B A\left(m^{2}\right)=\pi r^{2} * D B H(\mathrm{~cm})^{2} / 4$

Volume Estimation: Volume for each tree was estimated using Newton's formula

$$
V=\pi H\left(\frac{D b^{2}+4 D m^{2}+D t^{2}}{24}\right)
$$

Where $V$ is the stem volume $\left(\mathrm{m}^{3}\right), \mathrm{H}$ is the total height $(m), \quad D b$ is the diameter at base $(\mathrm{cm}), D m$ is the diameter at the middle $(\mathrm{cm})$, and $D t$ is the Diameter at the top $(\mathrm{cm})$.

Above Ground-ground Biomass (AGB) Calculation: The above-ground biomass (AGB) for each tree was estimated using the formula:

$$
\begin{aligned}
& \theta_{j}^{i+1}=\theta_{j}^{i}-\frac{\tau}{\sqrt{\left|m_{t}^{i+1}\right|+10 e^{-8}}} \frac{\partial}{\partial \theta_{j}} L\left(\theta_{0}, \theta_{1}\right) \\
& \text { For } j=0, \quad m_{t}^{i+1}=\beta m_{t}^{i}+(1-\beta) \frac{1}{n} \sum_{i=1}^{n}\left(Y_{\text {predicted }}-Y_{A G B}\right)
\end{aligned}
$$

Where $A G B(t / h a)$ measured in tonne per hectare is the aboveground biomass of the tree, $V$ is the volume of the tree $\left(\mathrm{m}^{3} / \mathrm{ha}\right)$ measured in cubic metre per hectare, $\rho$ is the specific wood density $\left(t / \mathrm{m}^{3}\right)$, and $B_{e f}$ is the biomass expansion factor.

Model Development: Let $Y_{A G B}$ and $X_{O A V}$ be independent variables denoting observations on AGB and a combination of other allometric variables $(\mathrm{OAV})$, respectively. Also, let the relation between $Y_{A G B}$ and $X_{O A V}$ be given by:

$Y_{A G B}=a_{0}+a_{1} X_{O A V}+e_{i}$

where $a_{0}$ and $a_{1}$ are unknown parameters for the function and $E_{\text {rror }}$ is a vector of measurement errors.

Loss Function: The loss function used is the Half Mean Squared Error (HMSE) and is defined as:

$L\left(\theta_{0}, \theta_{1}\right)=\frac{1}{2 n} \sum_{i=1}^{n}\left(Y_{\text {predicted }}-Y_{A G B}\right)^{2}$

Modified Root Mean Square Propagation (Modified RMSprop): The objective of RMSprop is to minimize (7). RMSprop is defined by Bubeck (2015) as:

$\theta_{j}^{i+1}=\theta_{j}^{i}-\frac{\tau}{\sqrt{m_{t}^{i+1}+10 e^{-8}}} \frac{\partial}{\partial \theta_{j}} L\left(\theta_{0}, \theta_{1}\right)$

Where $\theta_{j}^{i}$ represents the value of the $j^{\text {th }}$ coefficient of the $i^{\text {th }}$ iteration, $\tau$ is the learning rate and $m_{t}^{i+1}$ is defined as:

$m_{t}^{i+1}=\beta m_{t}^{i}+(1-\beta) \frac{\partial}{\partial \theta_{j}} L\left(\theta_{0}, \theta_{1}\right)$

$\beta$ is the exponential decay rate of the momentum $m_{t}$. According to Okonkwo et al. (2020), using the RMSprop algorithm as defined in (8) for traditional regression problems resulted in complex number regression coefficients due to the possibility of negative momentum $m_{t}$ in the algorithm. To solve this problem, we resorted to using Modified RMSprop which uses the absolute value of $\left|m_{t}^{i+1}\right|$. 
$\theta_{0}^{i+1}=\theta_{0}^{i}-\frac{\tau}{\sqrt{\left|m_{t}^{i+1}\right|+10 e^{-8}}} \frac{1}{n} \sum_{i=1}^{n}\left(Y_{\text {predicted }}-Y_{A G B}\right)$

For $j=1, \quad m_{t}^{i+1}=\beta m_{t}^{i}+(1-\beta) \frac{1}{n} \sum_{i=1}^{n}\left(Y_{\text {predicted }}-Y_{A G B}\right) X_{O A V}$

$\theta_{1}^{i+1}=\theta_{1}^{i}-\frac{\tau}{\sqrt{\left|m_{t}\right|}+10 e^{-8}} \frac{1}{n} \sum_{i=1}^{n}\left(Y_{\text {predicted }}-Y_{A G B}\right) X_{O A V}$

Modified Adaptive Moment Estimation (Modified Adam): The objective of Adam is to minimize (7). Adam is defined by Kingma and $\mathrm{Ba}$ (2017):

$\theta_{j}^{i+1}=\theta_{j}^{i}-\frac{\tau}{\sqrt{v_{t}^{i+1}}+10 e^{-8}} m_{t}^{i+1}$

Where $\theta_{j}^{i}$ represents the value of the $j^{\text {th }}$ coefficient of the $i^{\text {th }}$ iteration, $\tau$ is the learning rate. $m_{t}$ and $v_{t}$ are the respective first and second momentum of the cost function of the algorithm respectively defined as:

$$
\begin{aligned}
m_{t}^{i+1}=\beta_{1} m_{t}^{i}+\left(1-\beta_{1}\right) \frac{\partial}{\partial \theta_{j}} L\left(\theta_{0}, \theta_{1}\right) \\
\theta_{j}^{i+1}=\theta_{j}^{i}-\frac{\tau}{\sqrt{\left|v_{t}^{i+1}\right|+10 e^{-8}}} m_{t}^{i+1}
\end{aligned}
$$

Where $m_{t}, v_{t}$ and $\frac{\partial}{\partial \theta_{j}} L\left(\theta_{0}, \theta_{1}\right)$ are as defined above.

$$
\begin{aligned}
& \text { For } j=0, m_{t}^{i+1}=\beta_{1} m_{t}^{i}+\left(1-\beta_{1}\right) \frac{1}{n} \sum_{i=1}^{n}\left(Y_{\text {predicted }}-Y_{A G B}\right) \\
& v_{t}^{i+1}=\beta_{2} v_{t}^{i}+\left(1-\beta_{2}\right) \frac{1}{n} \sum_{i=1}^{n}\left(Y_{\text {predicted }}-Y_{A G B}\right) \\
& \theta_{0}^{i+1}=\theta_{0}^{i}-\frac{\tau}{\sqrt{\left|v_{t}^{i+1}\right|+10 e^{-8}} m_{t}^{i+1}} \\
& \text { For } j=1, m_{t}^{i+1}=\beta_{1} m_{t}^{i}+\left(1-\beta_{1}\right) \frac{1}{n} \sum_{i=1}^{n}\left(Y_{\text {predicted }}-Y_{A G B}\right) X_{O A V} \\
& v_{t}^{i+1}=\beta_{2} v_{t}^{i}+\left(1-\beta_{2}\right) \frac{1}{n} \sum_{i=1}^{n}\left(Y_{\text {predicted }}-Y_{A G B}\right) X_{O A V} \\
& \theta_{1}^{i+1}:=\theta_{1}^{i}-\frac{\tau}{\sqrt{\left|v_{t}^{i+1}\right|}+10 e^{-8}} m_{t}^{i+1}
\end{aligned}
$$

Data Analysis: Data analysis was carried out using GNU's Octave (Eaton et al., 2014). Data was split into two parts: training set $(80 \%)$ and validation set $(20 \%)$. Modified RMSProp and Modified Adam were used on the training set with a learning rate of 0.01 and exponential decay rates of 0.9 and 0.999 respectively for the first and second momentum of the algorithms. Modified RMSProp has just one momentum. The resulting estimated parameters were then used to create regression models between the dependent variable $(\ln (A G B))$ and the independent variable $\left(\ln (D), \ln (D H), \ln \left(D^{2} H\right), \ln \left(D^{2} H W\right)\right)$ of each allometric model. The input data from the validation set is then inputted in the regression model to predict $\ln (A G B)$ described as $\ln (\overline{A G B})$. The predicted values are compared with the test values and accuracy was measured with a Welch's t-test and Root Mean Square Error (RMSE).

\section{RESULTS AND DISCUSSION}

The optimization algorithms converged after a different number of iterations for each allometric model (Figure 3): Modified RMSProp converged after 1000 iterations while Modified Adam converged after 200 iterations. Both algorithms started from the same maximum loss of 8.7730 for all allometric models but converged to different minimum losses (Table 1). It can also be seen from Figure 3 that Model 1 has the lowest convergent rate, and the highest minimum loss for both algorithms (Table 1), while models 3 and 4 have the highest convergent rate for Modified RMSProp and Modified Adam respectively. 

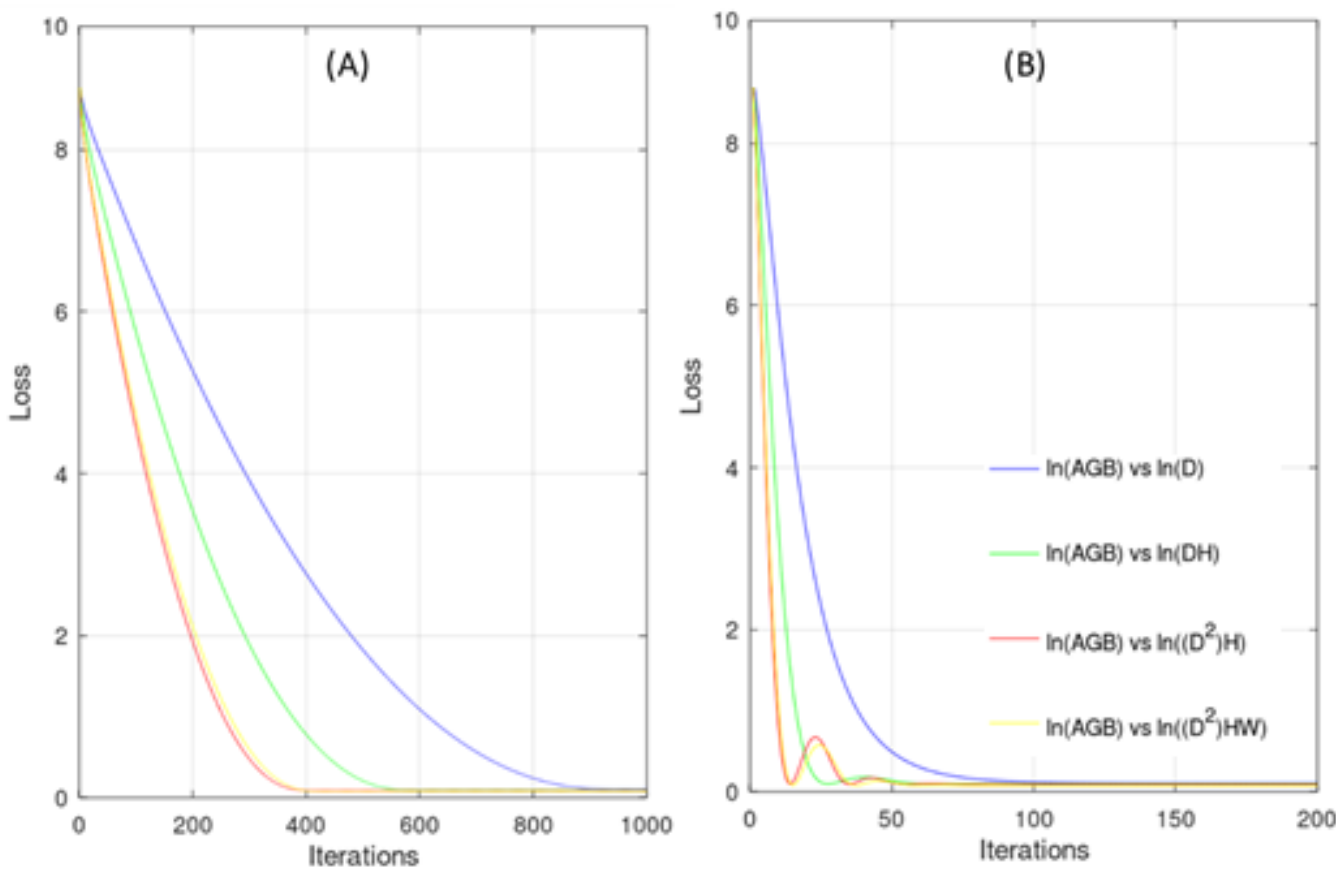

Fig 2. Convergence for each Algorithm. (A). Modified RMSProp (B). Modified Adam

From (Table 1) the estimated parameters for the slope $\theta_{0}$ and intercept $\theta_{1}$ of each allometric model are equal. The estimated parameters and the minimum loss from both optimization algorithms for each allometric model are approximately equal. The estimated parameters for Model 1 is: 0.90298 for Modified RMSProp and 0.90185 for Modified Adam, while the minimum loss for Model 1 is 0.10618 for Modified RMSProp and 0.10620 for Modified Adam. However,
Model 2, Model 3 and Model 4 respectively have the same minimum loss of $0.095934,0.091944$ and 0.077989 for both optimization algorithms. It can also be seen that Modified Adam had the highest RMSE value of 2.3910 for Model 4, while Modified RMSProp had the least RMSE value 0.37381 for Model 3 (Table 2).

Table 1. Descriptive Statistics and Parameter Estimates of the Models after Iterations.

\begin{tabular}{lccccccl}
\hline \multicolumn{2}{c}{} & \multicolumn{3}{c}{ RMSProp } & \multicolumn{3}{c}{ Adam } \\
\multicolumn{2}{c}{ Variables } & $\theta_{0}$ & $\theta_{1}$ & Min. Loss & $\theta_{0}$ & $\theta_{1}$ & Min. Loss \\
\hline $\ln (A G B)$ & $\ln (D)$ & 0.90298 & 0.90298 & 0.10618 & 0.90185 & 0.90185 & 0.10620 \\
$\ln (A G B)$ & $\ln (D H)$ & 0.55232 & 0.55232 & 0.095934 & 0.55252 & 0.55252 & 0.095934 \\
$\ln (A G B)$ & $\ln \left(D^{2} H\right)$ & 0.37311 & 0.37311 & 0.091944 & 0.37358 & 0.37358 & 0.091944 \\
$\ln (A G B)$ & $\ln \left(D^{2} H W\right)$ & 0.39189 & 0.39189 & 0.077989 & 0.39145 & 0.39145 & 0.077989 \\
\hline
\end{tabular}

The parameters for Model 2 are 0.55232 and 0.55252 for Modified RMSProp and Modified Adam respectively, while the parameters for Model 3 are 0.37311 and 0.37358 for Modified RMSProp and Modified Adam respectively. Model 4 has parameters
0.39189 and 0.39145 for Modified RMSProp and Modified Adam respectively. Model 1 has the highest minimum loss of 0.10620 for both algorithms while Model 4 has the least minimum loss of 0.077989 . 

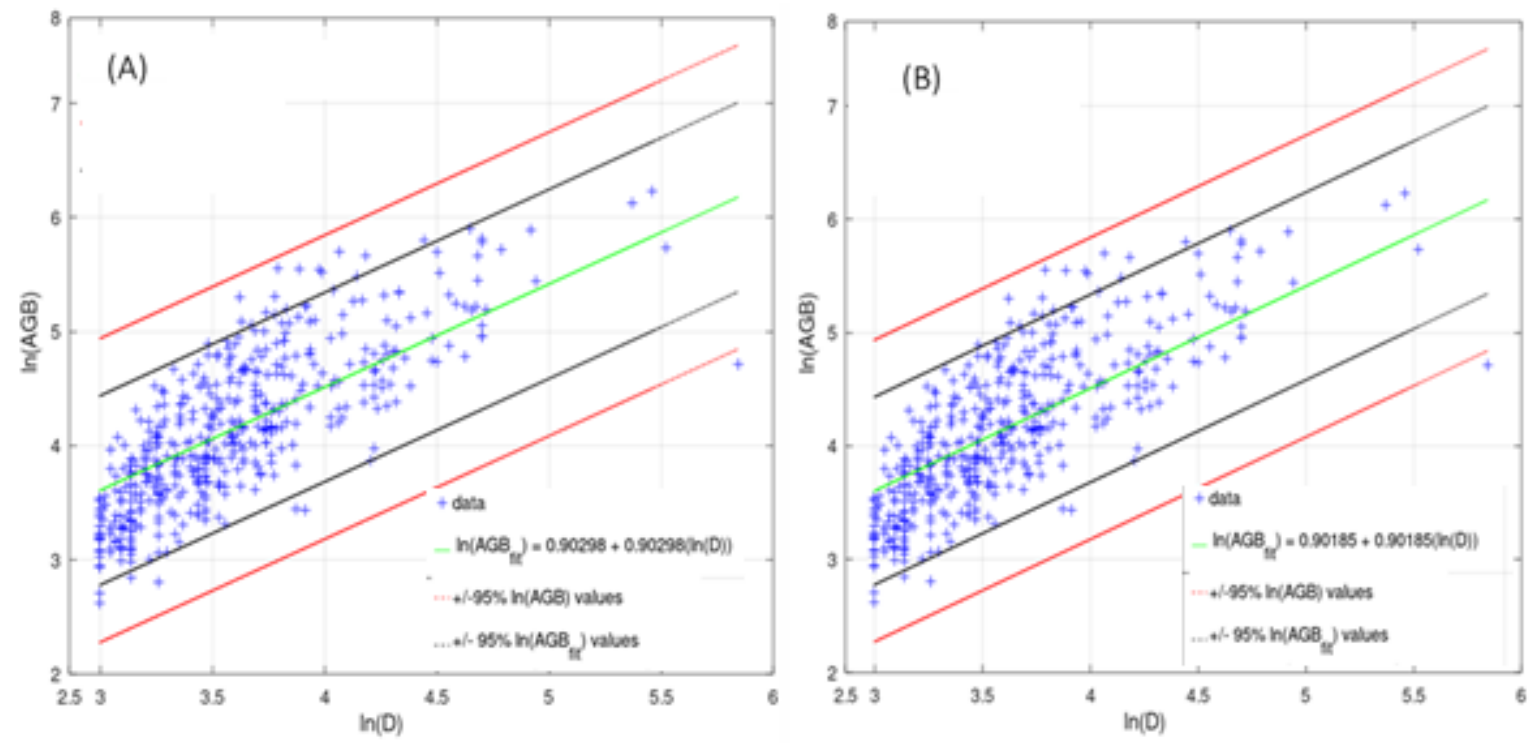

Fig 3: Regression Line with Model 1. (A). Modified RMSProp (B). Modified Adam

From (Table 2), except for Model 4, there was no statistically significant difference between the predicted and validation variables. Model 3 has the least validation error of 0.37381 and 0.37415 for Modified RMSProp and Modified Adam respectively followed by Model 2 with validation errors 0.39304 and 0.39313 for Modified RMSProp and Modified Adam. Model 1 has the second-highest validation error of 0.40149 and 0.40123 for Modified RMSProp and Modified Adam respectively.

Table 2: Test Accuracy for each Allometric model

\begin{tabular}{llllllll}
\hline & & \multicolumn{3}{c}{ RMSProp } & \multicolumn{3}{c}{ Adam } \\
& & T-statistic & p-value & RMSE & T-statistic & p-value & RMSE \\
\hline $\ln (A G B)_{\text {test }}$ & $\ln (\overline{A G B})_{1}$ & -0.45414 & 0.65024 & 0.40149 & -0.39178 & 0.69566 & 0.40123 \\
$\ln (A G B)_{\text {test }}$ & $\ln (\overline{A G B})_{2}$ & -0.50606 & 0.61340 & 0.39304 & -0.52411 & 0.60082 & 0.39313 \\
$\ln (A G B)_{\text {test }}$ & $\ln (\overline{A G B})_{3}$ & -0.45112 & 0.65242 & 0.37381 & -0.51373 & 0.60804 & 0.37415 \\
$\ln (A G B)_{\text {test }}$ & $\ln (\overline{A G B})_{4}$ & 31.817 & 0 & 2.3890 & 31.848 & 0 & 2.3910 \\
\hline
\end{tabular}
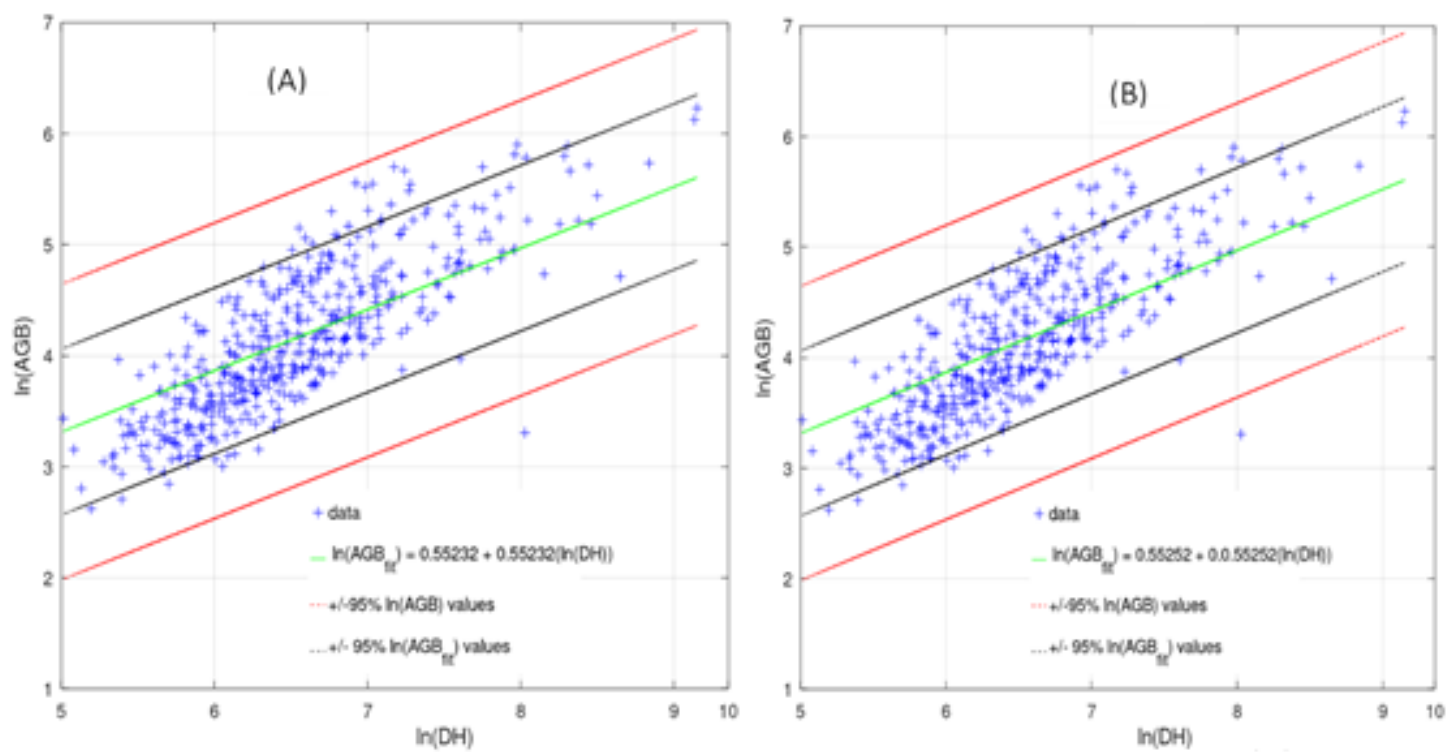

Fig 4: Regression Line with Model 2. (A). Modified RMSProp (B). Modified Adam 
Model 4 has the highest validation error of 2.3890 and 2.3910 for Modified RMSProp and Modified Adam respectively and there is a statistically significant difference between the predicted and validation data. This disparity between the predicted and validation values of Model 4 is most likely due to overfitting of the data during training since it has the fastest convergent rate for both algorithms, and the lowest training error but the highest validation error. Further investigation needs to be carried out on the model with fewer training iterations for both algorithms.

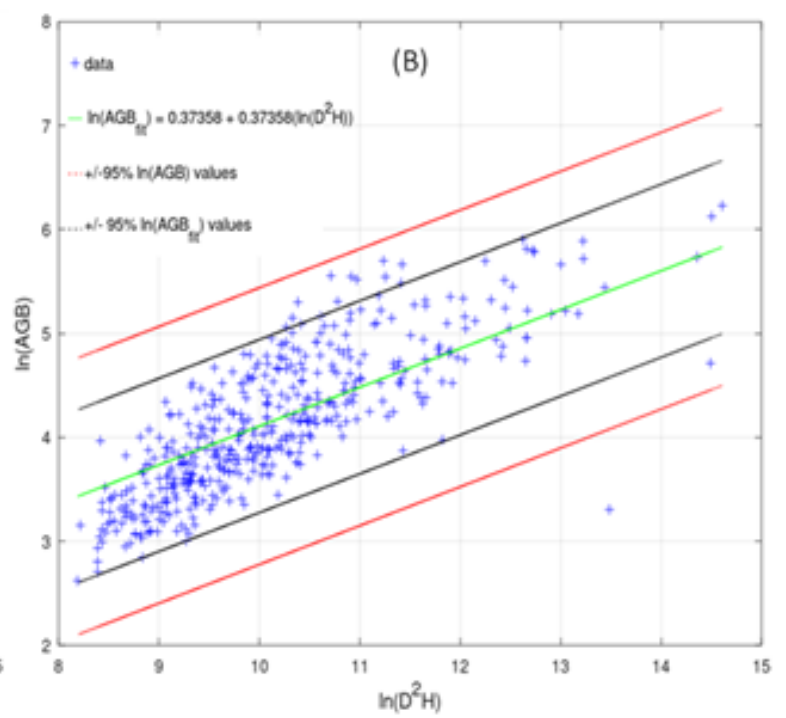

Fig 5: Regression Line with Model 3. (A). Modified RMSProp (B). Modified Adam

Conclusion: The study showed that the optimization algorithms were both able to accurately estimate the optimum parameters for three (out of four) allometric models with each fitting the data appropriately (Figure 4, and Figure 5). Modified Adam had the highest RMSE value 2.3910 for Model 4, while Modified RMSProp had the least RMSE value 0.37381 for Model 3. Except for Model 4, there was no statistically significant difference between the actual and the predicted values of the models optimized by both algorithms.

\section{REFERENCES}

Adedeji, OH; Tope-Ajayi, OO; Abegunde, OL (2015). Assessing and Predicting Changes in the Status of Gambari Forest Reserve, Nigeria Using Remote Sensing and GIS Techniques. J. Geogr. Inf. Syst. 7(3): 301-318.

Ali, I; Greifeneder, F; Stamenkovic, J; Neumann, M; Notarnicola, C (2015). Review of Machine Learning Approaches for Biomass and Soil Moisture Retrievals from Remote Sensing Data. Remote Sens. 7(12): 16398-16421.

Baghdadi, N; Le Maire, G; Bailly, J-S; Osé, K; Nouvellon, Y; Zribi, M; Lemos, C; Hakamada, R (2015). Evaluation of ALOS/PALSAR L-Band Data for the Estimation of Eucalyptus Plantations
Aboveground Biomass in Brazil. IEEE J. Sel. Top. Appl. Earth Obs. Remote Sens. 8(8): 3802-3811.

Brown, S (2002). Measuring carbon in forests: current status and future challenges. Environ. Pollut. 116(3): 363-372.

Bubeck, S (2015). Convex Optimization: Algorithms and Complexity. Found. Trends Mach. Learn. 8(34): 231-357.

Cao, L; Coops, N; Innes, JL; Sheppard, SRJ; Fu, L; Ruan, H; She, G (2016). Estimation of forest biomass dynamics in subtropical forests using multi-temporal airborne LiDAR data. Remote Sens. Environ. 178: 158-171.

Deng, S; Katoh, M; Guan, Q; Yin, N; Li, M (2014). Estimating Forest Aboveground Biomass by Combining ALOS PALSAR and WorldView-2 Data: A Case Study at Purple Mountain National Park, Nanjing, China. Remote Sens. 6(9): 78787910.

Dong, J; Kaufmann, RK; Myneni, RB; Tucker, CJ; Kauppi, PE; Liski, J; Buermann, W; Alexyev, V; Hughes, MK (2003). Remote sensing estimates of boreal and temperate forest woody biomass: 
carbon pools, sources, and sinks. Remote Sens. Environ. 84(3): 393-410.

Eaton, JW; Bateman, D; Hauberg, S; Wehbring, R (2014). GNU Octave version 3.8.1 manual: A high-level interactive language for numerical computations. CreateSpace Independent Publishing Platform. ISBN 1441413006.

Houghton, RA; Hall, F; Goetz, S J (2009). Importance of biomass in the global carbon cycle. J. Geophys. Res. Biogeosciences 114(G2): 1-13.

Kingma, DP; Ba, JL (2017). Adam: A Method for Stochastic arXiv:1424.6980v9[cs.LG].

Larinde, SL; Olasupo, OO (2011). Socio-Economic Importance of Fuelwood Production in Gambari Forest Reserve Area, Oyo State, Nigeria. J. Agric. Soc. Res. (JASR), 11(1).

Le Toan, T; Beaudoin, A; Riom, J; Guyon, D (1992). Relating forest biomass to SAR data. IEEE Trans. Geosci. Remote Sens. 30(2): 403-411.

Li, W; Chen, E; Li, Z; Ke, Y; Zhan, W (2015). Forest aboveground biomass estimation using polarization coherence tomography and PolSAR segmentation. Int. J. Remote Sens. 36(2): 530-550.

Lu, D (2006). The potential and challenge of remote sensing-based biomass estimation. Int. J. Remote Sens. 27(7): 1297-1328.
Lu, D; Batistella, M; Moran, E (2005). Satellite Estimation of Aboveground Biomass and Impacts of Forest Stand Structure. Photogramm. Eng. Remote Sens. 71(8): 967-974.

Okali, DUU; Oa-Adams, BA (1987). Tree population changes in treated rain forest at Omo Forest Reserve, Nigeria. J. Trop. Ecol. 3(4):291-313.

Okonkwo, S; Adedoyin, ED; Ayodele, OU; Abdulateef, S (2020). Linear Regression Modelling of Population and GDP Using Adaptive Learning Rate Optimization Algorithms. In: Amahia, GN; Adekeye, KS; Ayinde, K;

Adewara, AA;Agunbiade, DA (ed) Population Data for Informed National Planning and Development. Royal Statistical Society, Nigeria Local Group, p.50.

Shen, W; Li, M; Huang, C; Wei, A (2016). Quantifying Live Aboveground Biomass and Forest Disturbance of Mountainous Natural and Plantation Forests in Northern Guangdong, China, Based on Multi-Temporal Landsat,

PALSAR and Field Plot Data. Remote Sens. 8(7): 595.

West, PW (2015) Tree and Forest Measurement. Springer-Verlag Berlin Heidelberg. 